\title{
Research on the Elastic Properties of Discontinuous Contact Wire Rope for WR-CVT
}

\author{
Wu Zhang $\mathbb{D}^{1,2}$ Jingliang Wu $\mathbb{D}^{1},{ }^{1}$ Yishan Liu $\mathbb{D}^{1},{ }^{1}$ Shishan Sun $\mathbb{D}^{1},{ }^{1}$ and Yanping Jia $\mathbb{D}^{1}$ \\ ${ }^{1}$ School of Mechanical and Engineering, Xi'an University of Science and Technology, Xi'an 710054, China \\ ${ }^{2}$ The State Key Laboratory of Mechanical Transmissions, Chongqing University, Chong Qing400044, China \\ Correspondence should be addressed to Jingliang Wu; 1552625440@qq.com
}

Received 25 December 2020; Accepted 19 May 2021; Published 30 May 2021

Academic Editor: Guoqiang Xie

Copyright (c) $2021 \mathrm{Wu}$ Zhang et al. This is an open access article distributed under the Creative Commons Attribution License, which permits unrestricted use, distribution, and reproduction in any medium, provided the original work is properly cited.

This study mainly conducts the research on the discontinuous contact elastic properties of wire rope based on WR-CVT. The geometry model and finite element model of continuous contact and discontinuous contact of $2 / 3$ lay pitch wire rope are established. And the contact stress distribution of the steel wire is analyzed through 5 sections and 5 contact points. The results show that on the $\mathrm{C}-\mathrm{C}$ plane, the contact stress of the discontinuous contact model is $229.4 \mathrm{MPa}$ higher than that of the continuous contact, but this difference is not obvious on the $\mathrm{D}$-D plane. The contact stress nephogram is elliptical, but in the noncontact area, the shape of the contact trace shows a distinct noncomplete ellipse, and the contact trace is distributed along the spiral trajectory of the steel wire. Point 4 due to the reduction in contact area, compared with continuous contact, discontinuous contact shows a higher stress value. The geometric dimensions of the wear scars of continuous contact and discontinuous contact indicate that regardless of the length of the wear scar or the width of the wear scar, the geometric characteristics of steel wire wear mark in discontinuous contact are larger than that in continuous contact, so the discontinuous contact aggravates the surface wear of wire. This research lays a theoretical foundation for the discontinuous contact wear and fatigue of WR-CVT wire rope and other components.

\section{Introduction}

Steel wire rope is widely used in mine lifting, elevator, ropeway, and other industries due to its excellent tensile, torsion, and bending resistance. Its flexible characteristics are designed and applied to the wire rope continuously variable transmission (WR-CVT) [1]. The traditional wire rope is mostly used in cable car, mine hoisting, and other occasions. The wire rope is in contact with the pulley, and the pulley is continuous. The WR-CVT researched in this study is applied in the field of passenger car transmission. The pulley formed by multiple metal blocks is discontinuous in structure, as shown in Figure 1.

Metal belt continuously variable transmission (MBCVT) is widely used in passenger cars as an ideal vehicle transmission device, and our team scholars proposed WRCVT. Because WR-CVT is evolved from MB-CVT, WR-CVT is mainly used in passenger car transmission. Figure 2(a) shows the MB-CVT, Figure 2(b) shows the WR-CVT, Figure 3(a) shows the MB-CVT steel belt, and Figure 3(b) shows WR-CVT steel belt.

The wear of the steel wire rope is an important factor restricting the service life and reliability of the steel wire rope because the mechanical properties of the material have a decisive effect on the use of the steel wire rope. Chen et al. $[2,3]$ analyzed the bending mechanical properties of triangular and circular steel wire strands based on the structural characteristics of the strands, the elasticity of the steel wire material, and the frictional contact between the steel wires and other factors. The finite element models of two kinds of steel wire strands were established, and the bending mechanical properties of two kinds of steel wire strands with the same twist angle and total steel wire sectional area were analyzed. Zhang et al. [4] conducted a study on the wear failure behavior of wire rope subjected to variable loads under bending and found that the outer steel wire rope and 


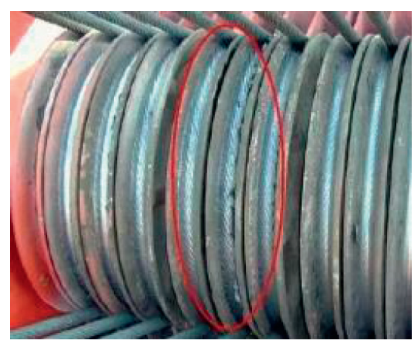

(a)

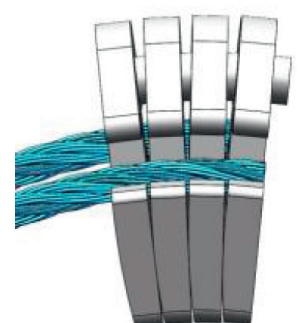

(b)

FIgURe 1: Application of continuous and discontinuous contact of wire rope with pulley and metal block. (a) Continuous contact between wire rope and hoist pulley. (b) Discontinuous contact between wire rope and multiple metal blocks for CVT.

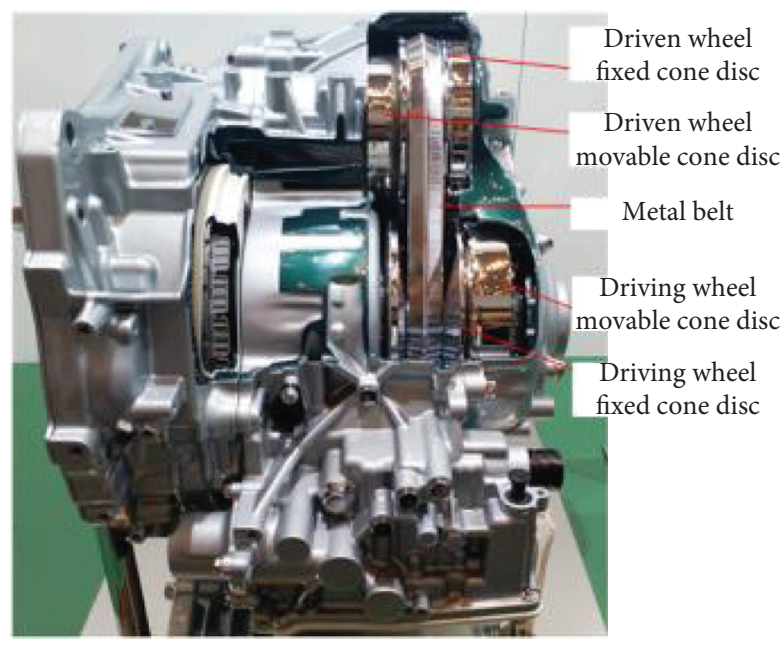

(a)

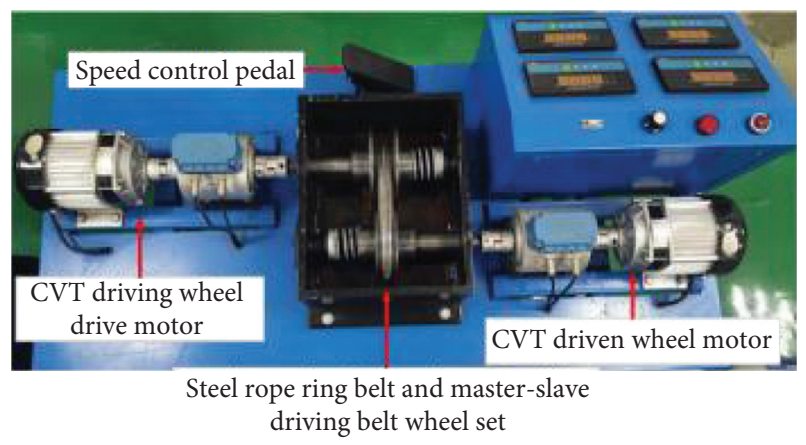

(b)

Figure 2: (a, b) MB-CVT and WR-CVT.

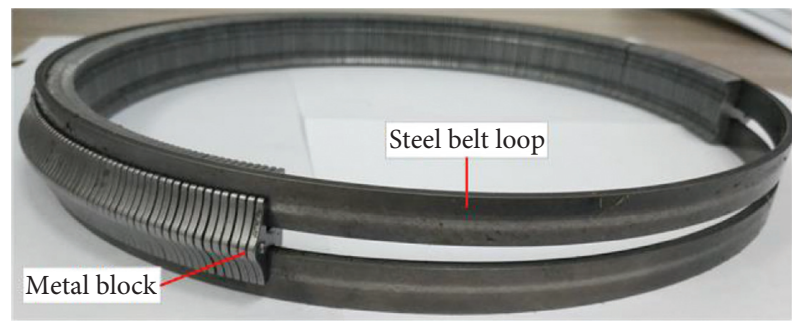

(a)

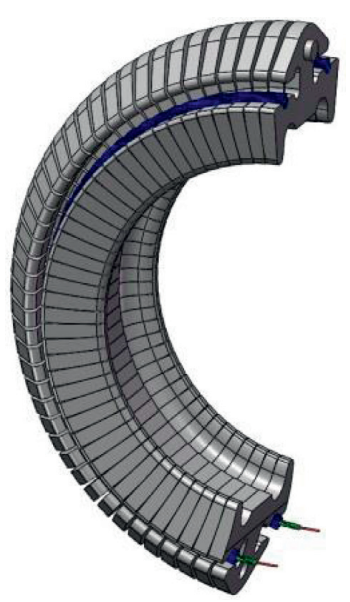

(b)

Figure 3: $(a, b)$ MB-CVT steel belt and WR-CVT steel belt.

the contact steel wire rope were important areas of serious wear and then carried out dynamic simulation and measurement of partial angle wear. Wu et al. [5] derived the space vector expression of the centerline of the secondary helix wire in the bending state and established a three- dimensional model of the $12-6 \times 7$ IWRC wire rope bending state and compared the difference of the equivalent stress change amplitude between the right ordinary lay and right lang lay wire ropes under the bending state. Li et al. [6] took $1+6$ steel wire rope as the research object based on the finite 
element simulation analysis that obtained the change rule of the tension of each wire in the strand with the ratio of the contact arc length of the wire rope head sheave to the rope lay pitch. In 2012, Cruzado et al. [7] conducted finite element modeling and experimental verification of $90^{\circ}$ cross cylinder wear steel wire based on FE code, studied the area, depth, and volume of wire wear scar from the reduction of simulation time and accurate calculation of wear scar, and found that the error could be controlled within $10 \%$. Two years later, the author [8] conducted simulation predictions with cross-angle for $15^{\circ}, 45^{\circ}$, and $60^{\circ}$ wire wear scar, and simulation wear scar size was basically consistent with the experimental results. Páczelt and Beleznai [9] developed a finite element program that considers factors such as nonlinear contact, Poisson effect, friction, and wear. This program can perform small displacement and deformation analysis of the wire rope under a variety of loads including tension, torsion, and bending.

Hirane et al. [10] discussed the stratified finite element formula for the static and free vibration analysis of functionally graded interlayers by using the $\mathrm{C} 0$ high-order stratified finite element model. The numerical results of the model are compared with the analytical solutions in the literature and the prediction results of other advanced finite element models. The results show that the FGM sandwich plate finite element model performs better in accuracy and convergence rate. Alimirzaei et al. [11] adopted the modified strain gradient theory and carried out nonlinear analysis on the static force, buckling, and vibration of the viscoelastic microcomposites reinforced by $\mathrm{BN}$ nanotubes with different distributions with geometric defects by the finite element method. The effects of initial geometric imperfections and different boundary conditions on the nonlinear static behavior are discussed. The results show that with the increase of geometric defect parameters, the stiffness of the microcomposite beam increases, and the dimensionless nonlinear frequency of the microstructure decreases gradually. Vaghefi [12] performed a three-dimensional thermoelastic-plastic bending analysis on a functionally graded (FG) sandwich panel with a functionally graded (FG) panel and an FG/ homogeneous core under the combined thermomechanical load. The deflection, temperature, and stress of FG sandwich plate were numerically analyzed with consideration of different material gradient, thickness ratio, and boundary conditions. The numerical results are in good agreement with those of $2 \mathrm{D}$, quasi-3D, and $3 \mathrm{D}$ shear deformation theories. Liu et al. [13] used the scale boundary finite element method (SBFEM) to analyze the free vibration and transient dynamic behavior of functionally graded material (FGM) sandwich plates. The results show that the dynamic response obtained by this method converges quickly and is in good agreement with the existing solutions, which indicates that this method has high accuracy and efficiency in the dynamic analysis of functionally graded material sandwich plates.

Scholars mostly study the mechanical analysis of wire rope in continuous state, but there are few studies on the condition of discontinuous contact. In the process of contacting with discontinuous metal block, the wire rope ring used in WR-CVT will produce the stress concentration phenomenon caused by edge contact, which has a great influence on the stress of steel wire (as shown in Figures 1(b) and 4). And it will also aggravate the wear degree of steel wire surface, reduce the bearing capacity of steel wire rope, and directly affect the reliability and service life of WR-CVT steel wire rope. So the research on the elastic characteristics of steel rope under continuous and discontinuous contact conditions in this study lays a theoretical foundation for exploring the load-bearing performance of steel rope, improving the mechanical properties of WR-CVT wire rope and predicting the wear law of steel rope.

\section{Geometric Model and Finite Element Model of Steel Wire Rope}

2.1. 3D Geometric Model and Plane Definition. As shown in Figure 5, in the Cartesian coordinate system (O: $x, y, z)$, there is a curve $f(\lambda)=(x(\lambda), y(\lambda), z(\lambda))$, where $\lambda$ is a function independent variable. Suppose there is a moving point Q on the curve. The normal vector, the subnormal vector, and the tangent vector at the Q point are $L, M$, and $N$, respectively. The local coordinate system $l, m, n$ composed of the unit vectors $l-m-n$ corresponding to these three orthogonal vectors is called the Frenet-Serret frame. The literature [14] uses the Frenet-Serret frame theory to derive the straight line and arc center line equations of the no-joint wire rope. The calculation formulas are as follows:

$$
\left\{\begin{array}{l}
L=\frac{f(\ddot{\lambda})}{\|f(\ddot{\lambda})\|}, \\
m=n \times l, \\
n=\frac{f(\ddot{\lambda})}{\|f(\ddot{\lambda})\|} .
\end{array}\right.
$$

Refer to reference [15] for detailed modeling equations of wire rope in this study. The geometric model of $6 \times 7+$ IWS right-hand ordinary lay wire rope is completed in the Cartesian coordinate system, and a discontinuous contact model of 2/3 lay length is formed by combining with the metal block. The specific modeling parameters are given in Table 1. Figure 6 is the nomenclature of steel wire in each section. Figure 7 is a metal block model, and Figure 8 is a $2 /$ 3lay length wire rope and metal block assembly model.

Figure 9 shows the three-dimensional model of continuous contact and discontinuous contact between the steel wire rope and the friction pulley. Define the following five sections: turn the initial A-A section clockwise by $3.27^{\circ}$ to get the $\mathrm{B}-\mathrm{B}$ section, rotate $\mathrm{A}-\mathrm{A}$ section by $3.88^{\circ}$ to get $\mathrm{C}-\mathrm{C}$ section, the D-D section is in the middle of the second metal block geometry, and E-E cross-section is on the right crosssection of the second metal block.

2.2. Continuous Contact and Discontinuous Contact Finite Element Model of 2/3 Lay Pitch. Figure 10 shows the 2/3 lay length continuous contact and discontinuous contact finite 


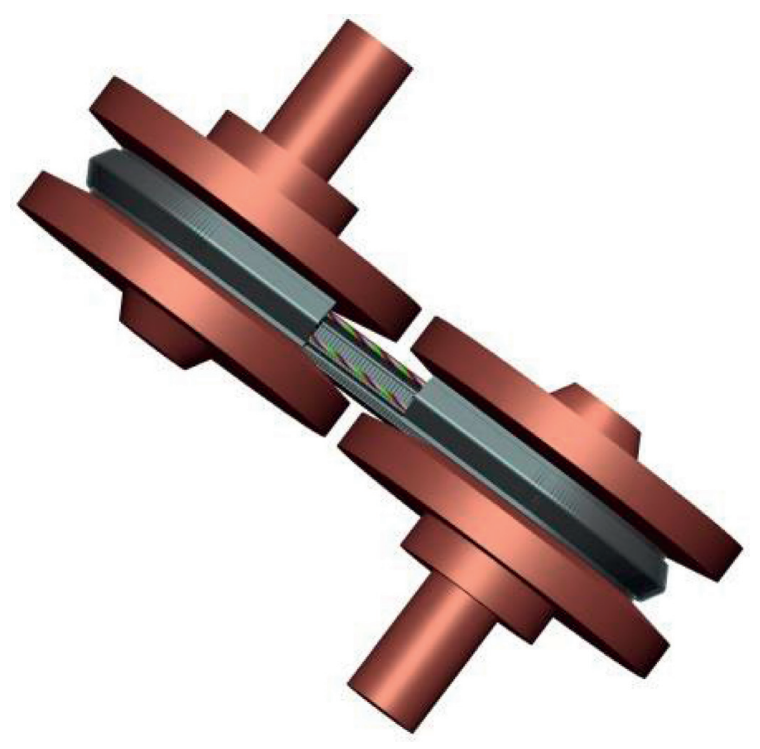

FIgURE 4: WR-CVT assembly.

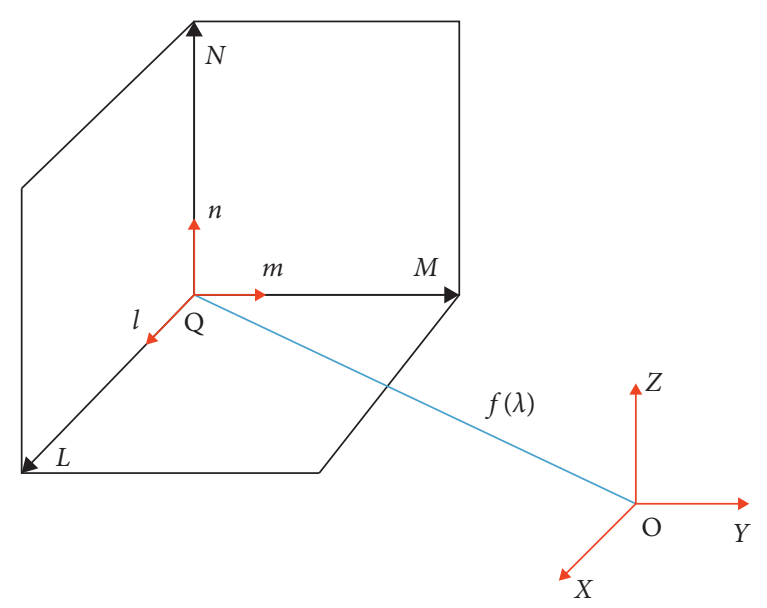

FIgURE 5: Frenet-Serret frame.

TABLE 1: Parameters of right-hand ordinary lay $6 \times 7+$ IWS .

\begin{tabular}{lcc}
\hline Parameter symbol & Value & Unit \\
\hline Rope diameter & 2 & $\mathrm{~mm}$ \\
Strand diameter & 0.66 & $\mathrm{~mm}$ \\
Wire diameter & 0.2 & $\mathrm{~mm}$ \\
Helix angle of wire rope & 16.5 & $\circ$ \\
Helix angle of strand & 11.1 & \\
Multiple of strand lay pitch & 7 & \\
Multiple of wire lay pitch & 10 & $\mathrm{~mm}$ \\
Strand clearance & 0.0222 & \\
\hline
\end{tabular}

element model. 3D mesh is done in Hypermesh software; then, import it into ABAQUS to assign attributes for finite element conditions, using hexahedron C3D8R grid, elastic modulus $E=2.06 \times 10^{11} \mathrm{~Pa}$, and Poisson's ratio $\mu=0.3$ [16]. Shear modulus is $G=8.53 \times 10^{10} \mathrm{~Pa}$. The yield limit is $\sigma_{\mathrm{s}}=1.54 \times 10^{9} \mathrm{~Pa}$. And steel wire material is nonalloy carbon steel. Coefficient of friction between metal block and wire rope is 0.2 , and the axial tension is $300 \mathrm{~N}$.

In the analysis, the metal block/rope groove is fixed, the steel wire rope has been fixed at one end, and the concentrated axial load is applied at the other end. The point of action is RP-2, and the freedom of the rope groove is equivalent to the freedom of the reference point RP-1, as shown in Figure 10(c).

\section{Stress-Strain Analysis of Continuous Contact and Discontinuous Contact Steel Wire with 2/ 3 Lay Length}

Figure 11 shows the Von Mises stress distribution law of the steel wire on the D-D cross-section during continuous contact and discontinuous contact. It can be seen from the figure that, whether it is consecutive contact or inconsecutive contact, the Von Mises stress of the core strand wire is less than that of the side strand wire. The maximum Von Mises stress in both contact states occurs on the OW4-4 steel wire in contact with the metal block/rope groove. In this section, the Von Mises stress is $967.9 \mathrm{MPa}$ during continuous contact, and the value is $977.4 \mathrm{MPa}$ for discontinuous contact. The Von Mises stress in noncontinuous contact is $0.97 \%$ higher than that in continuous contact. Therefore, under the same conditions, the difference in Von Mises stress on the D-D cross-section of the two models is small.

Figure 12 shows the contact stress nephogram of continuous and discontinuous contact metal block/rope groove surface. The larger value of the contact stress of the consecutive rope groove is located on the $\mathrm{B}-\mathrm{B}$ and $\mathrm{C}-\mathrm{C}$ sections, and the maximum contact stress value is $319.8 \mathrm{MPa}$. The larger value of the discontinuous rope groove contact stress is located on the $\mathrm{B}^{\prime}-\mathrm{B}^{\prime}$ and $\mathrm{C}^{\prime}-\mathrm{C}^{\prime}$ sections, and the maximum contact stress value is $549.2 \mathrm{MPa}$. Contact stress concentration occurs at the edge of the discontinuous metal block, and the contact stress is $229.4 \mathrm{MPa}$ higher than that of the continuous model. The contact between the surface of the steel wire rope and the friction pulley shows an elliptical high stress distribution [17], which is distributed along the direction of the steel wire spiral trajectory.

Figure 13 shows the continuous and discontinuous contact stress distribution of the steel wire rope, and five contact points are determined, respectively. The maximum stress of the wire rope in contact with the continuous groove is $418.4 \mathrm{MPa}$ on the $\mathrm{C}-\mathrm{C}$ section and that of the wire rope in contact with the discontinuous metal block is $525.5 \mathrm{MPa}$ on the $C^{\prime}-C^{\prime}$ section. The contact stress in the discontinuous contact is $107.1 \mathrm{MPa}$ higher than that in the continuous contact, with a difference of $20.38 \%$. The discontinuous 1,2 point contact stress nephogram is larger than the continuous 1,2 point contact stress nephogram. The discontinuous contact stress values of 1,2 , and 4 are $376.167 \mathrm{MPa}$, $337.443 \mathrm{MPa}$, and $471.775 \mathrm{MPa}$. Continuous 1,2 , and 4 contact stress values are $346.852 \mathrm{MPa}, 264 \mathrm{MPa}$, and 301.209 MPa. Among them, points 3 and 4 in Figure 13(a) are the contact points of the steel wire rope and the 


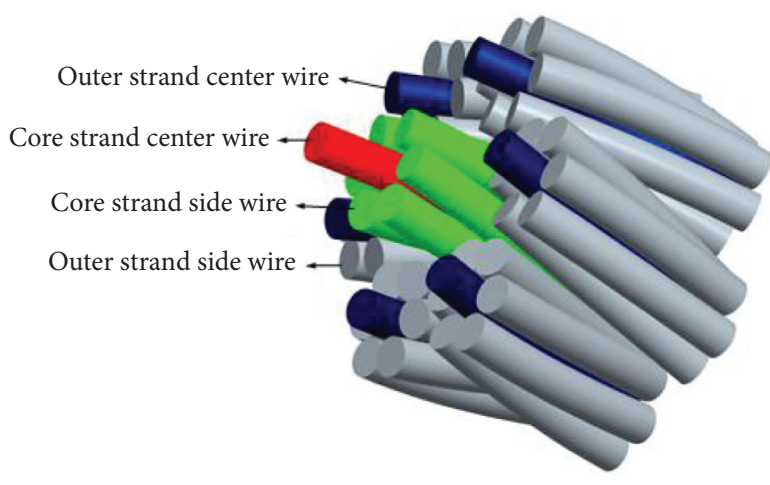

(a)

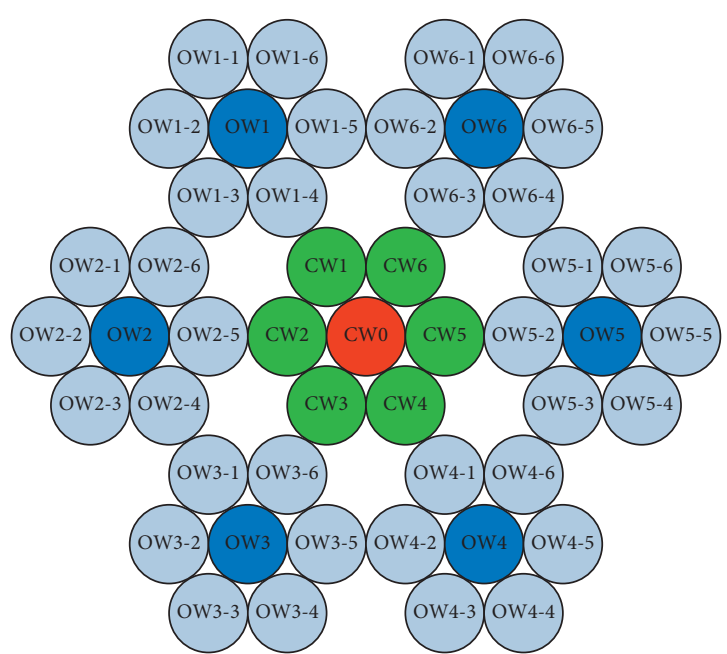

(b)

FigURE 6: $6 \times 7+$ IWS wire name and number. (a) $6 \times 7+$ IWS wire rope, four types of steel wire naming. (b) Wire number.

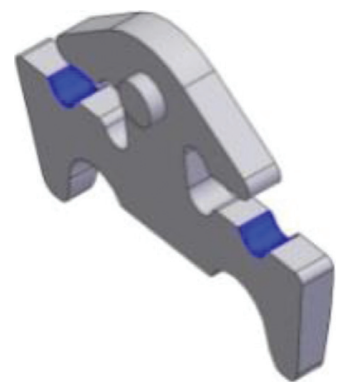

Figure 7: Metal block model.
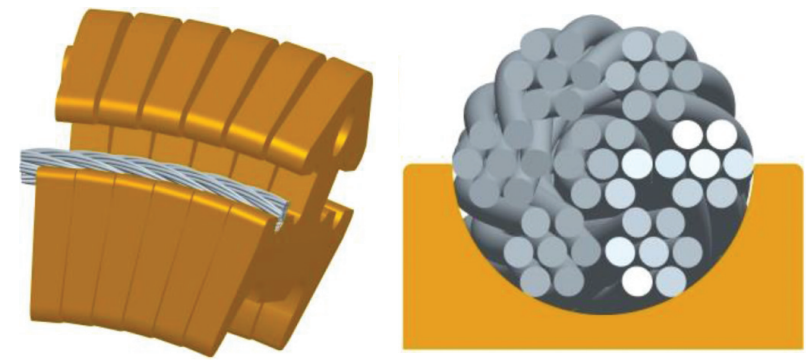

Figure 8: 2/3 lay length wire rope and metal block assembly model.

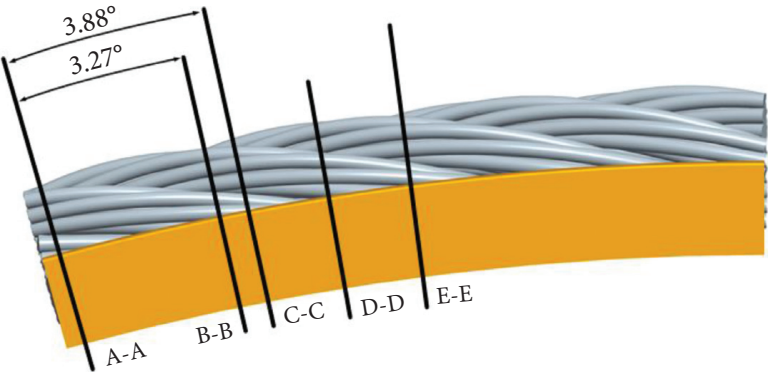

(a)

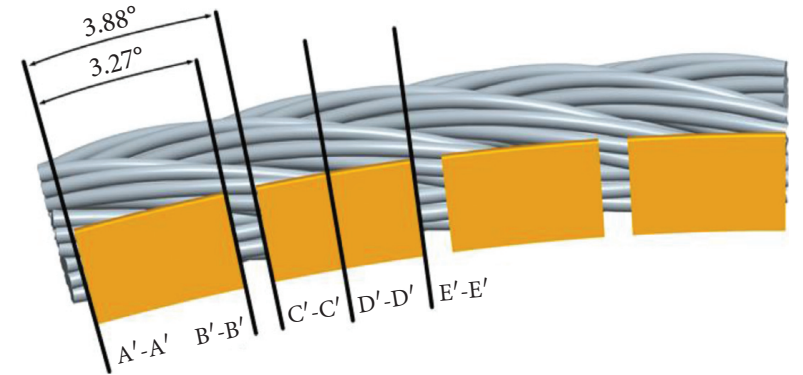

(b)

Figure 9: Sectional definition of the 3D model of continuous and discontinuous steel ring. (a) Sectional division of the continuous contact model. (b) Sectional division of the discontinuous contact model. 


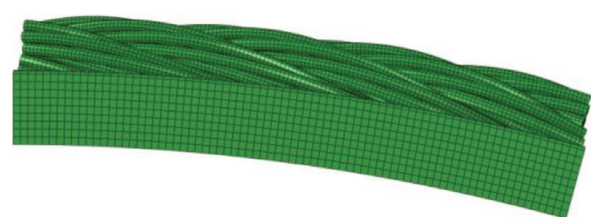

(a)

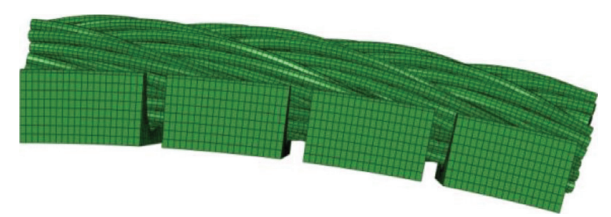

(b)

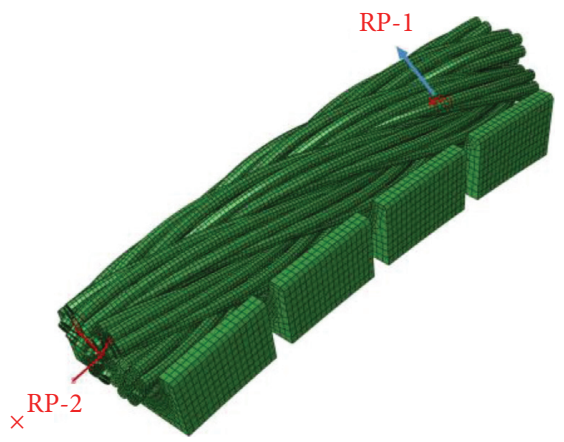

(c)

Figure 10: Contact finite element model of continuous and discontinuous steel wire rope. (a) Continuous contact grid model with $2 / 3$ lay length. (b) Discontinuous contact grid model of 2/3 lay length. (c) Finite element mesh of the discontinuous contact model.

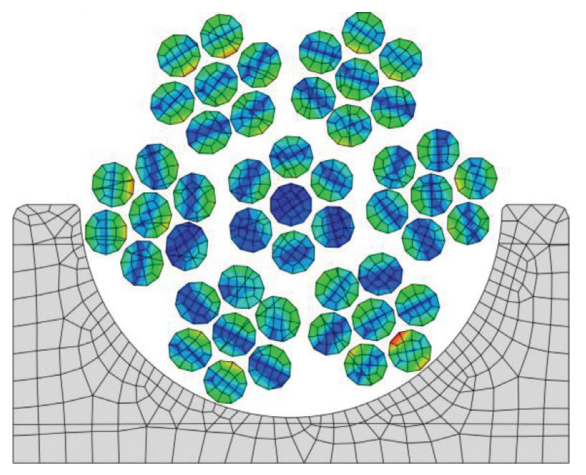

(a)
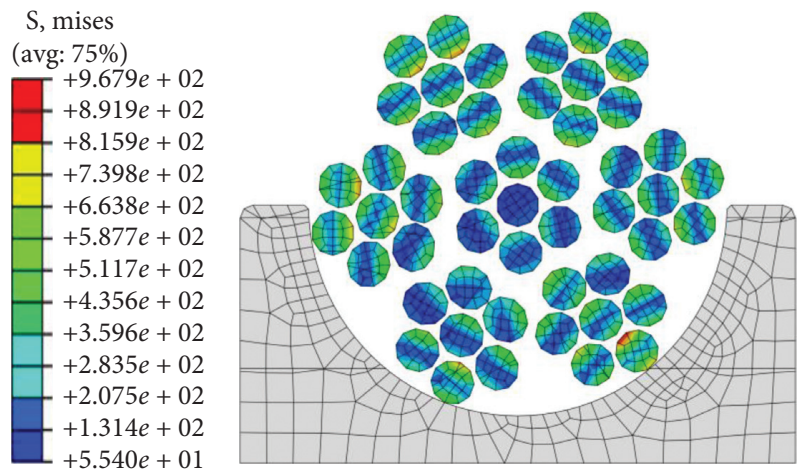

(b)

Figure 11: Von Mises stress of the continuous and discontinuous contact model of D-D cross-section. (a) Von Mises stress in the continuous contact model. (b) Von Mises stress in the discontinuous contact model.

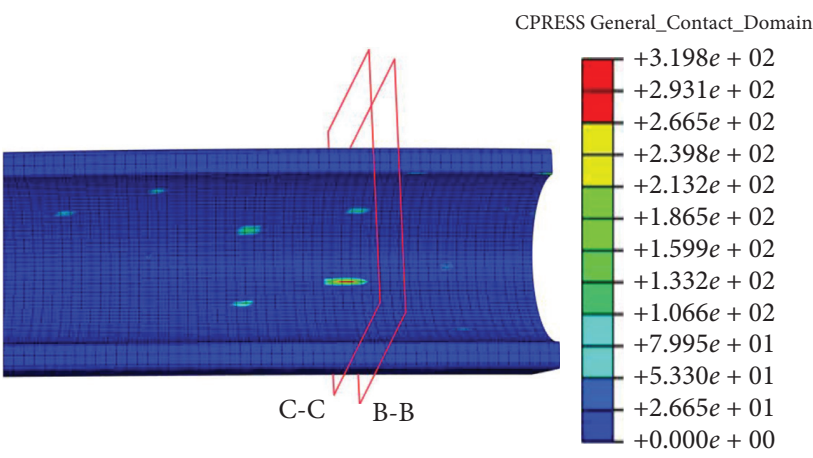

(a)

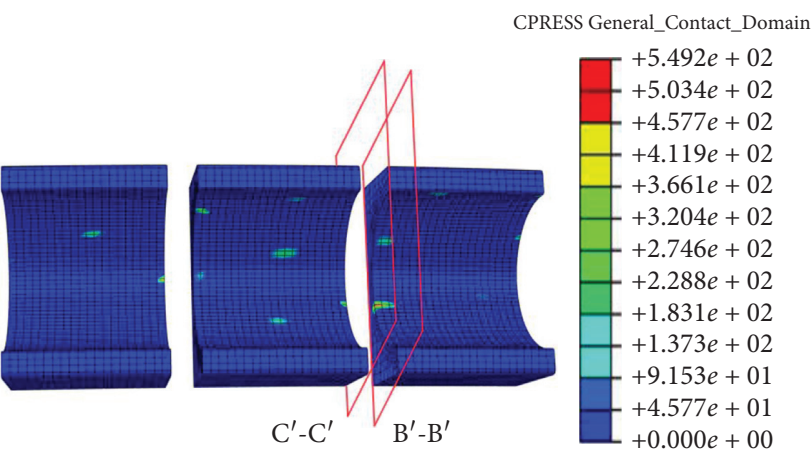

(b)

FIGURE 12: Contact stress nephogram of continuous and discontinuous rope grooves. (a) Contact stress distribution of the continuous rope groove contact model. (b) Contact stress distribution of the discontinuous rope groove contact model. 


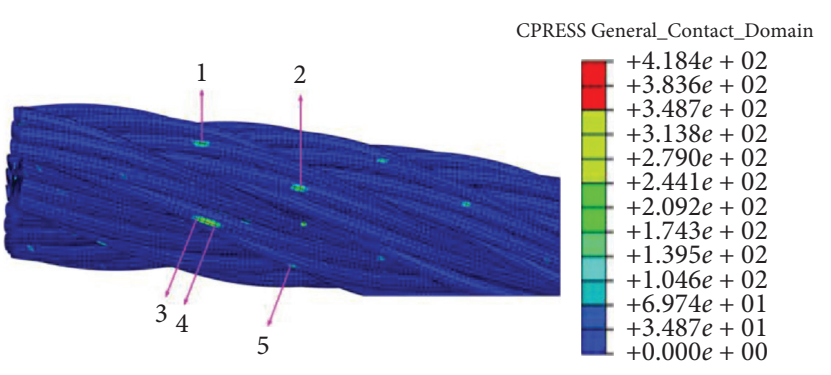

(a)

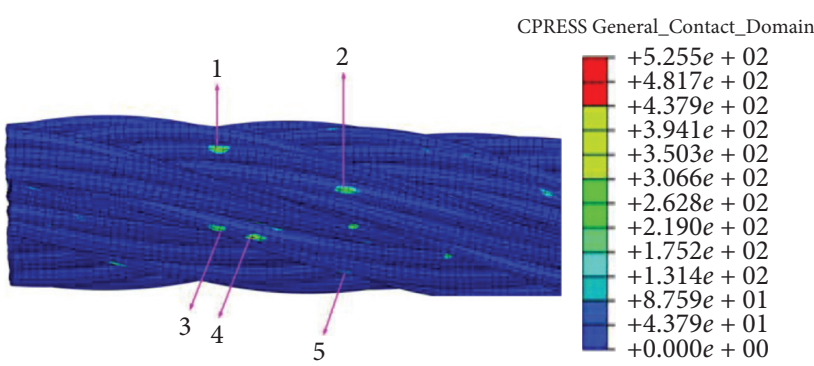

(b)

Figure 13: Comparison of contact stress on continuous and discontinuous wire rope. (a) Contact stress distribution on the continuous model wire rope. (b) Contact stress distribution on the discontinuous model wire rope.

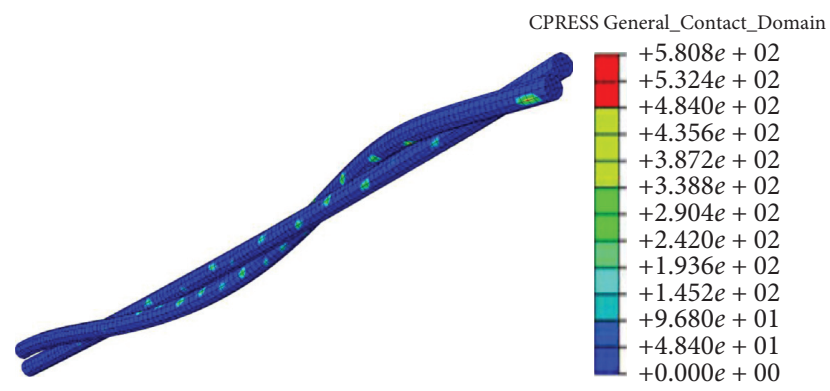

FIGURE 14: Contact stress between core wire and side wire of wire rope.

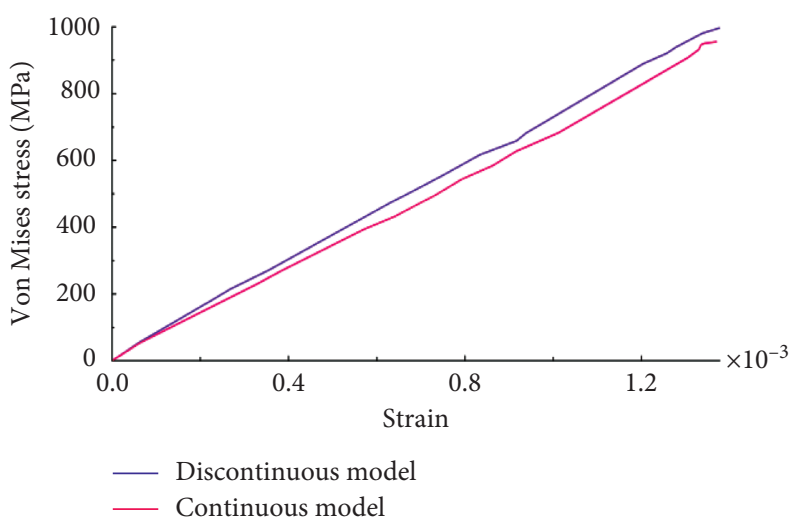

Figure 15: Comparison of continuous and discontinuous Von Mises Stress and strain.

continuous rope groove, and points 3 and 4 in Figure 13(b) are the contact points of the steel wire rope and the edge of the discontinuous rope groove. It can be seen from the figure that the contact point of each wire rope is not on a certain wire due to the wire rope structure. At the same time, due to the reduction of the contact area during discontinuous contact, the contact point has a higher contact stress value than the continuous contact point. And the shape of the contact scar shows an incomplete ellipse, which is also shown in Figure 12.

Figure 14 shows the contact stress distribution on the surface of core strand center wire and core strand side wire. The contact stress nephogram on the surface of the core strand is elliptical. The core strand side wire is in contact with the core strand center wire and the adjacent side strand side wire; therefore, the contact stress nephogram of different sizes appears on the steel wire surface, and it shows that each part of the wire is not uniformly subjected to contact load, so the wear scar size of the steel wire will be different during the wear process.

Figure 15 shows the continuous and discontinuous Von Mises Stress and strain of steel wire rope. Under the condition of friction, the Von Mises Stress of steel wire increases approximately linearly until plastic deformation occurs, the effect of the rope groove makes the discontinuous model yield first. Under the same axial strain condition, the radial equivalent stress difference between the two finite element models is not obvious in the linear stage, except the local contact area of the above discontinuous rope groove. In this model, the elastic property stage [18] is mainly considered, 


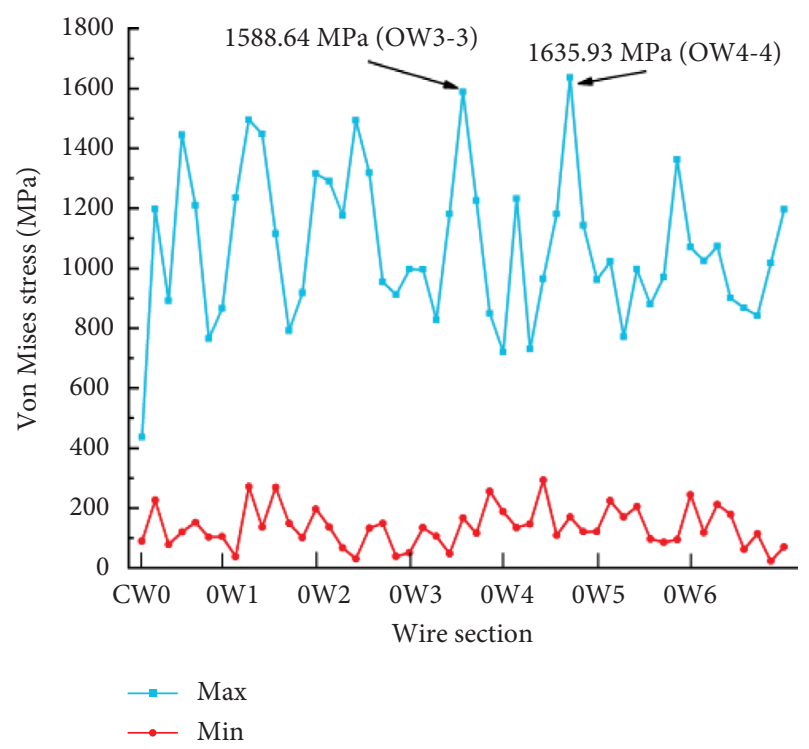

(a)

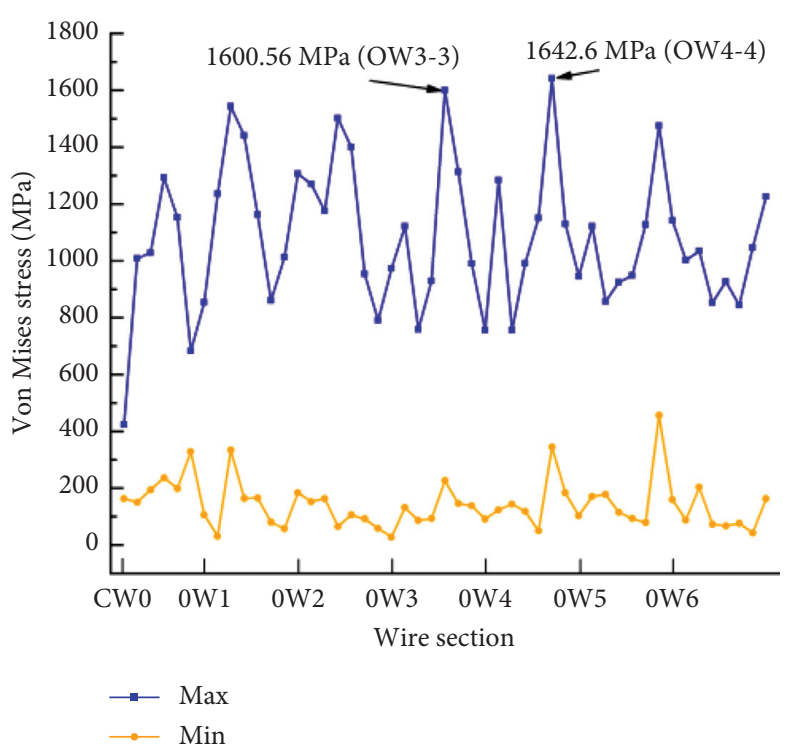

(b)

Figure 16: Von Mises Stress of each section of continuous and discontinuous rope. (a) Von Mises Stress of continuous rope section. (b) Von Mises Stress of discontinuous rope section.
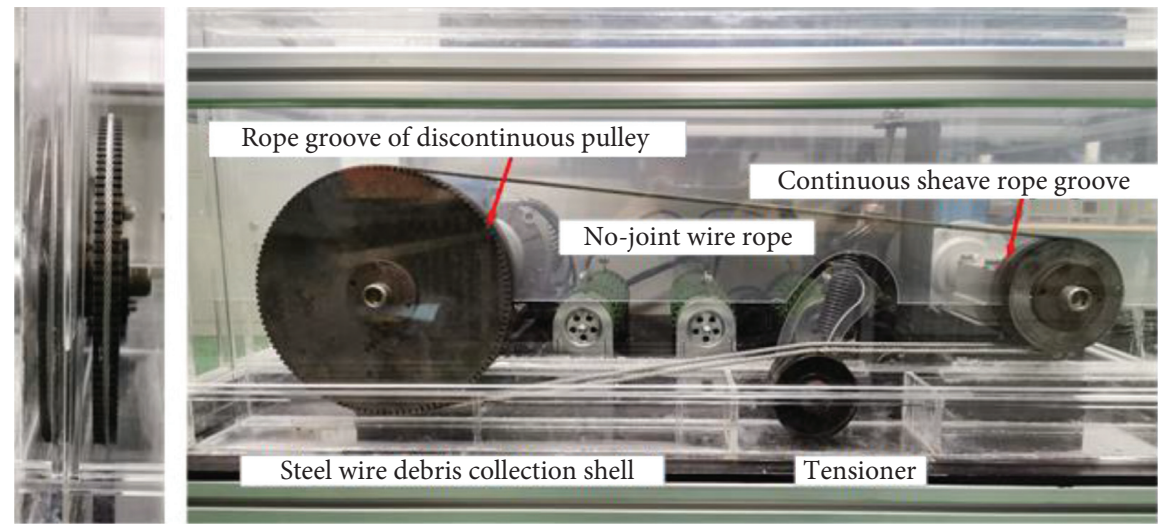

Figure 17: Continuous contact and discontinuous contact test bench for steel wire rope.

so the steel wire after plastic deformation is not studied in depth.

Figure 16 shows the Von Mises Stress comparison between continuous and discontinuous steel wire rope sections. It can be seen from the figure that the discontinuous model OW4-4 is $1642.6 \mathrm{MPa}$, while the continuous one is $1635.93 \mathrm{MPa}$. The commonality of the two cases is that the stress of the core strand steel wire is at a medium level, and both OW3-4 and OW4-4 have higher stresses, and OW4-4 in Figure 16(b) is slightly higher than Figure 16(a), which is the difference brought by the two contact pulley grooves. It is also shown in the figure that the core stress of each steel wire is not the largest, and the Von Mises Stress increases in turn along the radial radius direction of the steel wire. Since the minimum stress of the discontinuous contact wire rope in each section is larger than that of the continuous model, the stress level of the wire rope near the groove contact area is higher than that far away from the groove, which also shows that the wire rope is more prone to wear fatigue failure in the contact area.

\section{Characteristic Analysis of Continuous and Discontinuous Contact Wear Scar of Steel Wire Rope}

4.1. Continuous and Discontinuous Contact Test Bench for Steel Wire Rope. As shown in Figure 17, the steel wire rope continuous contact and discontinuous contact test bench is composed of motor, load loader, continuous pulley, and discontinuous pulley, and it also includes two steel wire ropes, tensioning device, and other auxiliary devices. The driving wheels of continuous and discontinuous pulleys are coaxial and driven by motor. And the driven wheels of continuous and discontinuous pulleys are coaxial, and they 

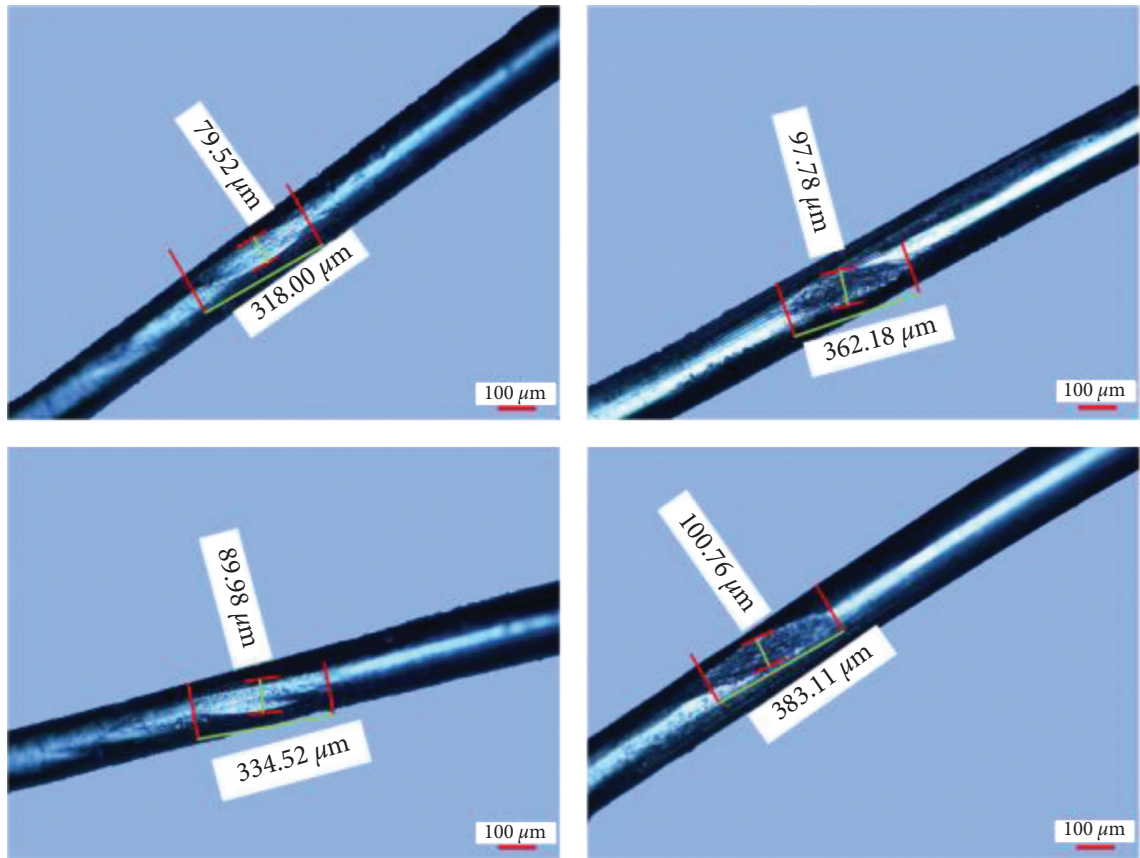

(a)
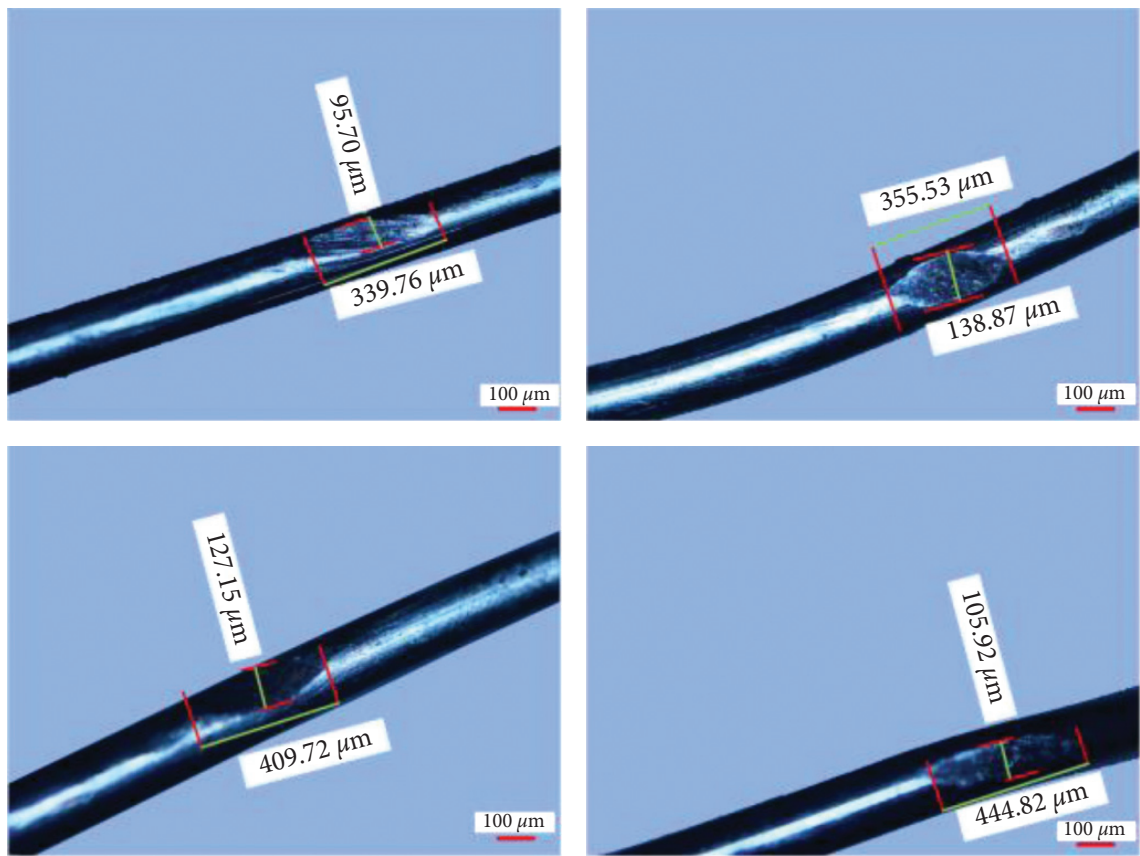

(b)

Figure 18: Comparison of surface wear scars of continuous and discontinuous steel wire. (a) Wear scar on the worn surface of steel wire rope in continuous contact. (b) Wear scar on the worn surface of steel wire rope in discontinuous contact.

are coaxial with the load loader. The wear experiment of the two models of wire rope under the same torque and speed driven by the motor and the start and end of the cycle time are equally controlled.

4.2. Morphological Analysis of Wear and Scar on the Surface of Continuous and Discontinuous Contact Steel Wire Rope. After the experiment, the NiKon-MA200 metallographic microscope was used to observe the characteristics of the wear scar, and 4 samples of continuous and discontinuous contact steel wire surface wear marks were selected for comparison as shown in Figure 18. The length and width and average value of continuous and discontinuous wire wear scar are given in Table 2. The length of the discontinuous contact wear scar is larger than that of the continuous contact, and its value is $38 \mu \mathrm{m}$, exceeding $10.87 \%$. The width of discontinuous contact wear scar is larger than that of continuous contact, and the value is $24.9 \mu \mathrm{m}$, more than 
TABLE 2: Continuous and discontinuous wire wear scar length and width and average value.

\begin{tabular}{lcccccc}
\hline Wear scar & Wire type & \multicolumn{2}{c}{ Value $(\mu \mathrm{m})$} & Average $(\mu \mathrm{m})$ \\
\hline \multirow{2}{*}{ Length } & Continuous & 318 & 362.18 & 334.52 & 383.11 & 349.5 \\
& Discontinuous & 339.76 & 355.53 & 409.72 & 444.82 & 387.5 \\
\hline \multirow{2}{*}{ Width } & Continuous & 79.52 & 97.78 & 89.98 & 100.76 & 105.92 \\
& Discontinuous & 95.7 & 138.87 & 127.15 & 92.01 \\
\end{tabular}

$27 \%$. No matter the length or width of the wear scar, the geometric characteristics of the steel wire wear scar in discontinuous contact are greater than that in continuous contact. Therefore, the discontinuous contact aggravates the surface wear of the steel wire, which may lead to the early fracture or fatigue of the discontinuous contact steel wire.

\section{Conclusions}

In this study, the discontinuous contact elastic characteristics of the wire rope based on WR-CVT are studied. Through the establishment of the geometric model and the finite element model of continuous contact and discontinuous contact of $2 / 3$ lay length, five sections and five contact points are divided, and then, the contact stress distribution of steel wire is analyzed. The conclusions are as follows:

(1) The maximum stress of wire rope on C-C section is 418.4 MPa, the maximum stress of wire rope on $\mathrm{C}^{\prime}-\mathrm{C}^{\prime}$ section is $525.5 \mathrm{MPa}$, and the contact stress in discontinuous contact is $107.1 \mathrm{MPa}$ higher than that in continuous contact, with a difference of $20.38 \%$. The contact stress nephogram shows an elliptical shape, but in noncontact area, the contact trace presents an incomplete ellipse. The contact trace is distributed along the direction of wire spiral trajectory. The maximum stress of the wire rope on the D-D section is $967.9 \mathrm{MPa}$, and the maximum stress of the wire rope on the $\mathrm{D}^{\prime}-\mathrm{D}^{\prime}$ section is $977.4 \mathrm{MPa}$, with a difference of $0.97 \%$.

(2) Due to the small contact area, the contact stress of point 4 on the discontinuous contact wire rope was $471.775 \mathrm{MPa}$, which was $170.566 \mathrm{MPa}$ larger than that of $301.209 \mathrm{MPa}$ in continuous contact, with a difference of $36.15 \%$. The above two points all indicate that the discontinuous contact condition of the wire rope is worse than the continuous contact condition.

(3) The wear length and width of discontinuous contact steel wire surface are $10.87 \%$ and $27 \%$ higher than that of continuous contact steel wire surface. The geometric dimensions of the wear scars of continuous contact and discontinuous contact indicate that, regardless of the length or width of the wear scar, the geometric characteristics of the steel wire wear scar in discontinuous contact are greater than in continuous contact, so discontinuous contact aggravates the surface wear of steel wire.

\section{Data Availability}

The data used to support the findings of this study are available from the corresponding author upon request.

\section{Conflicts of Interest}

The authors declare that they have no conflicts of interest.

\section{Acknowledgments}

The research was supported by Outstanding Youth Science Fund of Xi'an University of Science and Technology (2019YQ2-12), Shanxi Key Research and Development Program (2018GY-163 and 2020QFY03-06), Xi'an Science and Technology Plan Project (2019217714GXRC013CG014GXYD13.7), and Open Fund of State Key Laboratory of Mechanical Transmission (SKLMT-KFKF-201810).

\section{References}

[1] W. Guo, X. Xu, W. Zhang et al., "Analysis of the axial deviation of the steel rope ring of the steel rope ring CVT," China Mechanical Engineering, vol. 23, 2016.

[2] Y. Chen, Z. Chen, P. Meng et al., "Finite element comparative study on bending performance of triangular and circular steel wire strands," Journal of China University of Mining and Technology, vol. 44, no. 6, pp. 1105-1112, 2015.

[3] Y. Chen, F. Meng, and X. Gong, "Interwire wear and its influence on contact behavior of wire rope strand subjected to cyclic bending load," Wear, vol. 368-369, pp. 470-484, 2016.

[4] J. Zhang, D. Wang, D. Song et al., "Tribo-fatigue behaviors of steel wire rope under bending fatigue with the variable tension," Wear, vol. 428-429, pp. 154-161, 2019.

[5] J. Wu, Z. Kou, Y. Liu et al., "Numerical simulation of stress and strain of steel wire in the strand of bent steel wire rope," Journal of Coal Industry, vol. 40, no. 6, pp. 1463-1468, 2015.

[6] L. Li, D. Zhao, J. Li et al., "Simulation and experiment of wire tension change in bending wire rope strand," China Mechanical Engineering, vol. 29, no. 19, pp. 5-12, 2018.

[7] A. Cruzado, M. A. Urchegui, and X. Gómez, "Finite element modeling and experimental validation of fretting wear scars in thin steel wires," Wear, vol. 289, pp. 26-38, 2012.

[8] A. Cruzado, M. A. Urchegui, and X. Gómez, "Finite element modeling of fretting wear scars in the thin steel wires: Application in crossed cylinder arrangements," Wear, vol. 318, no. 1-2, pp. 98-105, 2014.

[9] I. Páczelt and R. Beleznai, "Nonlinear contact-theory for analysis of wire rope strand using high-order approximation in the FEM," Computers and Structures, vol. 89, no. 11-12, pp. 1004-1025, 2011.

[10] H. Hirane, M.-O. Belarbi, M. S. A. Houari, and A. Tounsi, "On the layerwise finite element formulation for static and free vibration analysis of functionally graded sandwich plates," Engineering with Computers, pp. 1-29, 2021.

[11] S. Alimirzaei, M. Mohammadimehr, and A. Tounsi, "Nonlinear analysis of viscoelastic micro-composite beam with geometrical imperfection using FEM: MSGT electro-magneto-elastic bending, buckling and vibration solutions," 
Structural Engineering and Mechanics, vol. 71, no. 5, pp. 485-502, 2019.

[12] R. Vaghefi, "Thermo-elastoplastic analysis of functionally graded sandwich plates using a three-dimensional meshless model," Composite Structures, vol. 242, Article ID 112144, 2020.

[13] J. Liu, C. Hao, W. Ye, F. Yang, and G. Lin, "Free vibration and transient dynamic response of functionally graded sandwich plates with power-law nonhomogeneity by the scaled boundary finite element method," Computer Methods in Applied Mechanics and Engineering, vol. 376, Article ID 113665, 2021.

[14] W. Zhang, X. Zhang, C. Zhang, and J. Zhang, “Theory and implementation of no-joint wire rope spatial geometry modeling," Mathematical Problems in Engineering, vol. 2019, Article ID 8760578, 11 pages, 2019.

[15] W. Zhang, C. Zhang, W. Guo, X. Xu, and Z. Lu, "Research on modeling and bending stress distribution of a new metal belt continuously variable transmission," Mechanism and Machine Theory, vol. 116, pp. 220-233, 2017.

[16] E. Stanova, G. Fedorko, M. Fabian, and S. Kmet, "Computer modelling of wire strands and ropes part II: finite elementbased applications," Advances in Engineering Software, vol. 42, no. 6, pp. 322-331, 2011.

[17] V. Ivanco, S. Kmet, and G. Fedorko, "Finite element simulation of creep of spiral strands," Engineering Structures, vol. 117, pp. 220-238, 2016.

[18] C. Erdonmez and C. E. Imrak, "A finite element model for independent wire rope core with double helical geometry subjected to axial loads," Sadhana, vol. 36, no. 6, pp. 995-1008, 2011. 